\title{
Metabolic and Molecular Events Occurring during Chromoplast Biogenesis
}

\author{
Wanping Bian, ${ }^{1,2}$ Cristina Barsan, ${ }^{1,2}$ Isabel Egea, ${ }^{1,2}$ Eduardo Purgatto, ${ }^{3}$ Christian Chervin,, 2 \\ Mohamed Zouine, ${ }^{1,2}$ Alain Latché, ${ }^{1,2}$ Mondher Bouzayen, ${ }^{1,2}$ and Jean-Claude Pech ${ }^{1,2}$ \\ ${ }^{1}$ Génomique et Biotechnologie des Fruits, INP-ENSA Toulouse, Université de Toulouse, avenue de l'Agrobiopole BP 32607, \\ Castanet-Tolosan 31326, France \\ ${ }^{2}$ Génomique et Biotechnologie des Fruits, INRA, Chemin de Borde Rouge, Castanet-Tolosan 31326, France \\ ${ }^{3}$ Departmento de Alimentos e Nutrição Experimental, Faculdade de Ciências Farmacêuticas, Universidade de São Paulo, \\ Avenue Prof. Lineu Prestes 580, bl 14, 05508-000 São Paulo, SP, Brazil \\ Correspondence should be addressed to Jean-Claude Pech, pech@ensat.fr
}

Received 13 January 2011; Accepted 3 June 2011

Academic Editor: William K. Smith

Copyright () 2011 Wanping Bian et al. This is an open access article distributed under the Creative Commons Attribution License, which permits unrestricted use, distribution, and reproduction in any medium, provided the original work is properly cited.

Chromoplasts are nonphotosynthetic plastids that accumulate carotenoids. They derive from other plastid forms, mostly chloroplasts. The biochemical events responsible for the interconversion of one plastid form into another are poorly documented. However, thanks to transcriptomics and proteomics approaches, novel information is now available. Data of proteomic and biochemical analysis revealed the importance of lipid metabolism and carotenoids biosynthetic activities. The loss of photosynthetic activity was associated with the absence of the chlorophyll biosynthesis branch and the presence of proteins involved in chlorophyll degradation. Surprisingly, the entire set of Calvin cycle and of the oxidative pentose phosphate pathway persisted after the transition from chloroplast to chromoplast. The role of plastoglobules in the formation and organisation of carotenoid-containing structures and that of the Or gene in the control of chromoplastogenesis are reviewed. Finally, using transcriptomic data, an overview is given the expression pattern of a number of genes encoding plastid-located proteins during tomato fruit ripening.

\section{Introduction}

Chromoplasts are nonphotosynthetic plastids that accumulate carotenoids and give a bright colour to plant organs such as fruit, flowers, roots, and tubers. They derive from chloroplasts such as in ripening fruit [1], but they may also arise from proplastids such as in carrot roots [2] or from amyloplasts such as in saffron flowers [3] or tobacco floral nectaries [4]. Chromoplasts are variable in terms of morphology of the carotenoid-accumulating structures and the type of carotenoids $[5,6]$. For instance, in tomato, lycopene is the major carotenoid, and it accumulates in membrane-shaped structures [7] while in red pepper beta-carotene is prominent and accumulates mostly in large globules [8]. Reviews specifically dedicated to the biogenesis of chromoplasts have been published [9-11]. Some information can also be found in papers dedicated to plastid differentiation in general
$[12,13]$. Thanks to transcriptomics and proteomics approaches, novel information is now available on the biochemical and molecular aspects of chromoplasts differentiation [14-16]. The present paper will review these novel data and provide a recent view of the metabolic and molecular events occurring during the biogenesis of chromoplasts and conferring specificities to the organelle. Focus will be made on the chloroplast to chromoplast transition.

\section{Chromoplast Differentiation Is Associated with Important Structural, Metabolic, and Molecular Reorientations}

Important structural changes occur during the chloroplast to chromoplast transition, thylakoid disintegration being the most significant (Figure 1). Early microscopic observations 


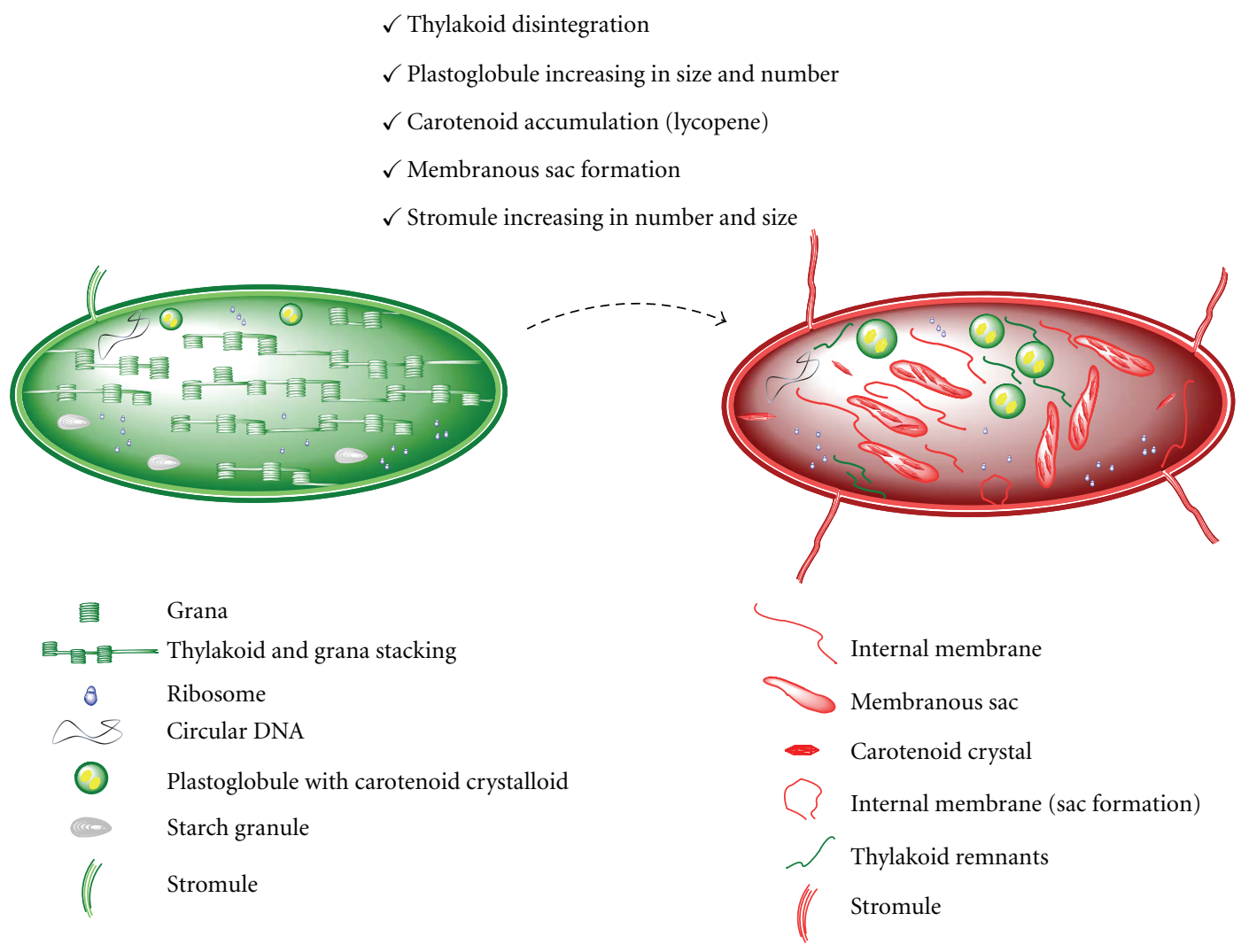

FIGURE 1: Schematic representation of the main structural changes occurring during the chloroplast to chromoplast transition.

have shown that plastoglobuli increase in size and number during the chloroplast-chromoplast transition [7] and that the internal membrane system is profoundly affected at the level of the grana and intergrana thylakoids [17]. Stromules (stroma-filled tubules) that are dynamic extensions of the plastid envelope allowing communication between plastids and other cell compartments like the nucleus [18] are also affected during chromoplastogenesis. A large number of long stromules can be found in mature chromoplasts contrasting with the few small stromules of the chloroplasts in green fruit [19]. It can therefore be assumed that the exchange of metabolites between the network of plastids and between the plastids and the cytosol is increased in the chromoplast as compared to the chloroplast. However, the most visible structural change is the disruption of the thylakoid grana, the disappearance of chlorophyll, and the biogenesis of carotenoid-containing bodies. Associated with the structural changes, the toc/tic transmembrane transport machinery is disintegrated $[16,20]$. The noncanonical signal peptide transport [21] and intracellular vesicular transport [22, 23] may represent the most active form of trans-membrane transport into the chromoplast as compared to the chloroplast. Proteins involved in vesicular transport were detected in the tomato chromoplastic proteome [16].

One of the most visible metabolic changes occurring during the chloroplast to chromoplast transition is the loss of chlorophyll and the accumulation of carotenoids [24]. A spectral confocal microscopy analysis of carotenoids and chlorophylls has been carried out during the chloroplast to chromoplast transition in tomato fruit, including a timelapse recording on intact live tissue [25]. Details of the early steps of tomato chromoplast biogenesis from chloroplasts are provided at the cellular level that show the formation of intermediate plastids containing both carotenoids and chlorophylls. This study also demonstrated that the chloroplast to chromoplast transition was synchronous for all plastids of a single cell and that all chromoplasts derived from preexisting chloroplasts.

The photosynthetic machinery is strongly disrupted and a reduction in the levels of proteins and mRNAs associated with photosynthesis was observed [26]. Also the decrease in photosynthetic capacity during the later stages of tomato fruit development was confirmed by transcriptomic data [27]. However, part of the machinery persist in the chromoplast. It has been suggested that it participates in the production of $\mathrm{C} 4$ acids, in particular malate a key substrate for respiration during fruit ripening [28]. In the tomato chromoplast proteome, all proteins of the chlorophyll biosynthesis branch are lacking [16]. In the early stages of tomato fruit ripening, the fruits are green and the plastids contain low levels of carotenoids that are essentially the same as in green leaves, that is, mainly $\beta$-carotene, lutein, and violaxanthin. At the "breaker" stage of ripening, lycopene begins to accumulate and its concentration increases 500fold in ripe fruits, reaching $c a .70 \mathrm{mg} / \mathrm{g}$ fresh weight [24]. During the ripening of tomato fruit, an upregulation of 
the transcription of Psy and $P d s$, which encode phytoene synthase and phytoene desaturase, respectively, was reported [29]. One of the main components of the carotenoid-protein complex, a chromoplast-specific $35-\mathrm{kD}$ protein $(\mathrm{chrC})$, has been purified and characterized in Cucumis sativus corollas. It showed increasing steady-state level in parallel with flower development and carotenoid accumulation, with a maximum in mature flowers [30]. In tomato, concomitantly with increased biosynthesis of lycopene, the processes for splitting into $\beta$ and $\gamma$ carotene were absent [16]. The mRNAs of $C r t L-b$ and $C r t L-e$ were strongly downregulated during fruit ripening [29]. They encode lycopene $\beta$-cyclase and $\varepsilon$-cyclase, enzymes involved in the cyclization of lycopene leading to the formation of $\beta$ and $\delta$ carotene, respectively. In these conditions, the low rate of cyclization and splitting contributes to the accumulation of lycopene in ripe tomato fruit.

In terms of reactive oxygen species, antioxidant enzymes are upregulated during chromoplast development, and lipids, rather than proteins, seem to be a target for oxidation. In the chromoplasts, an upregulation in the activity of superoxide dismutase and of components of the ascorbateglutathione cycle was observed [31].

The plastid-to-nucleus signaling also undergoes important changes. In the chromoplast, the main proteins involved in the synthesis of Mg-protoporphyrin IX, a molecule supposed to play an important role in retrograde signaling [32] is absent, but other mechanisms such as hexokinase 1 or calcium signaling were present [16]. The plastid-nucleus communication is still an open subject with many still unanswered questions.

\section{A Number of Metabolic Pathways Are Conserved during Chromoplast Differentiation}

The comparison of data arising from proteomics of the chloroplast [33] and of the chromoplast [16] as well as biochemical analysis of enzyme activities suggest that several pathways are conserved during the transition from chloroplast to chromoplast. Such is the case for (i) the Calvin cycle which generates sugars from $\mathrm{CO}_{2}$, (ii) the oxidative pentose phosphate pathway (OxPPP) which utilizes the 6 carbons of glucose to generate 5 carbon sugars and reducing equivalents, and (iii) many aspects of lipid metabolism (Figure 2). Activities of enzymes of the Calvin cycle have been measured in plastids isolated from sweet pepper. They may even be higher in chromoplasts than in chloroplasts [34] In ripening tomato fruits, several enzymes of the Calvin cycle (hexokinase, fructokinase, phosphoglucoisomerase, pyrophosphate-dependent phosphofructokinase, triose phosphate isomerase, glyceraldehyde 3-phosphate dehydrogenase, phosphoglycerate kinase, and glucose 6-phosphate dehydrogenase) are active [35]. The activity of glucose 6-phosphate dehydrogenase (G6PDH), a key component of the OxPPP, was higher in fully ripe tomato fruit chromoplasts than in leaves or green fruits [36]. Also, a functional oxidative OxPPP has been encountered in isolated buttercup chromoplasts [37]. Proteomic analysis have demonstrated that an almost complete set of proteins involved in the OxPPP are present in isolated tomato fruit chromoplasts (Figure 2). The persistence of the Calvin cycle and the OxPPP cannot be related to photosynthesis since the photosynthetic system is disrupted. In nonphotosynthetic plastids, the Calvin cycle could provide reductants and also precursors of nucleotides and aromatic aminoacids to allow the OxPPP cycle to function optimally [16].

Starch transiently accumulates in young tomato fruit and undergoes almost complete degradation by maturity. In fact, starch accumulation results from an unbalance between synthesis and degradation. Enzymes capable of degrading starch have been detected in the plastids of tomato fruit. In addition, tomato fruit can synthesize starch during the period of net starch breakdown, illustrating that these two mechanisms can coexist [38]. As indicated in Figure 3, proteins for starch synthesis have been encountered in the tomato chromoplast (ADP-glucose pyrophosphorylase, starch synthase, and starch branching enzyme). In addition, the system for providing neutral sugars to the starch biosynthesis pathway is complete including the glucose-6Ptranslocator which imports sugars from the cytosol. The presence of active import of glucose-6P, but not glucose1P, had been demonstrated in buttercup chromoplasts [37]. Although some starch granules may be present in ripe tomatoes, the amount of starch is strongly reduced [39]. The most probable explanation is that starch undergoes rapid turnover with intense degradation. This assumption is supported by the presence in the tomato chromoplast of most of the proteins involved in starch degradation (Figure 3). Particularly interesting is the presence of one glucan-water dikinase (GWD), one phospho-glucan-dikinase (PWD), and one phospho-glucan-phosphatase (PGP) that facilitate the action of $\beta$-amylases [40]. Mutants of these proteins, named starch excess (SEX1 corresponding to GWD and SEX4 to PGP), accumulate large amounts of starch [40]. In agreement with the above-mentioned hypothesis, high activity of $\beta$ amylase has been found during apple and pear fruit ripening at a time where starch has disappeared [41]. The presence of a glucose translocator for the export of sugars generated by starch degradation represents another support to the functionality of the starch metabolism pathways in chromoplasts. In olive fruit, a high expression of a glucose transporter gene was observed at full maturity when the chromoplasts were devoid of starch [42]. Nevertheless, the enzymatic activity of all of the proteins remains to be demonstrated inasmuch as posttranslational regulation of enzymes of starch metabolism has been reported [43] including protein phosphorylation [44]. Interestingly, orthologs of the 14-3-3 proteins of the $\mu$ family of Arabidopsis involved in the regulation of starch accumulation [45] are present in the tomato chromoplastic proteome (Figure 3). The 14-3-3 proteins participate in the phosphorylation-mediated regulatory functions in plants.

In chloroplasts, thylakoid membranes, as well as envelope membranes, are rich in galactolipids and sulfolipids [46]. Lipid metabolism is also highly active in the chromoplasts. Despite thylakoid disassembly, new membranes are synthesized such as those participating in the formation of 


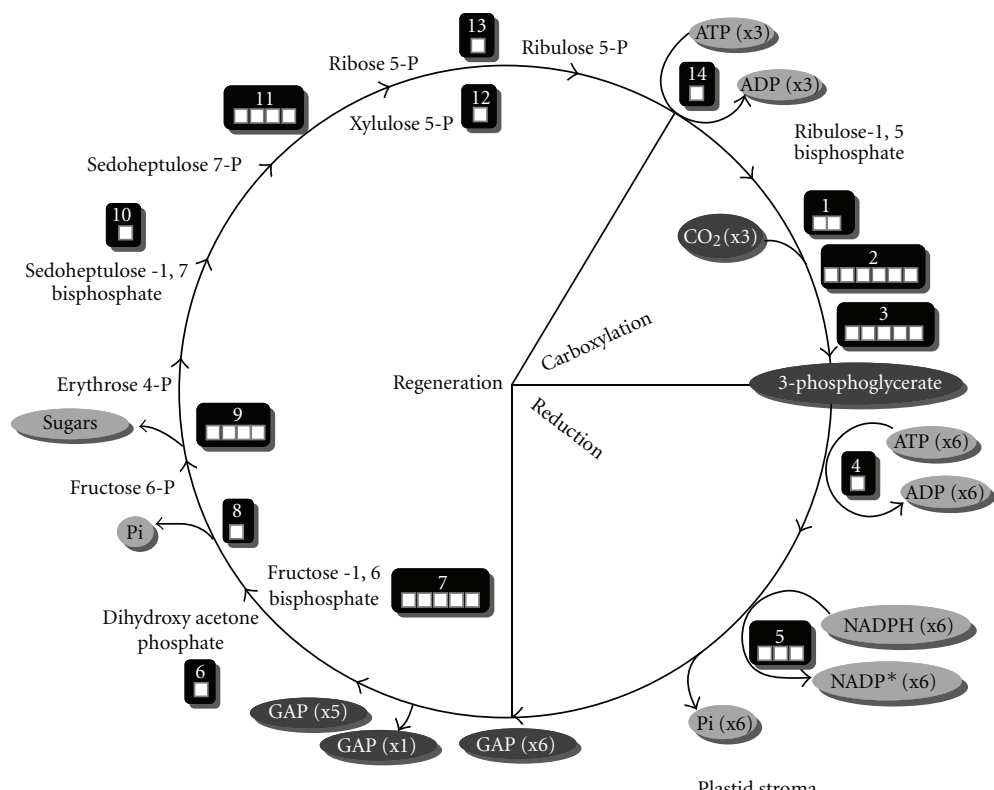

(a)

\begin{tabular}{|c|c|c|}
\hline \multicolumn{3}{|r|}{ Carboxylation } \\
\hline 1 & SGN-U346314 & large subunit of RUBISCO \\
\hline 2 & SGN-U314262 & ribulose bisphosphate carboxylase small chain $1 \mathrm{~A}$ \\
\hline 2 & SGN-U314254 & ribulose bisphosphate carboxylase small chain $1 \mathrm{~A}$ \\
\hline 2 & SGN-U314701 & ribulose bisphosphate carboxylase small chain 3B \\
\hline 2 & SGN-U314722 & ribulose bisphosphate carboxylase small chain 3B \\
\hline 2 & SGN-U314700 & ribulose bisphosphate carboxylase small chain 3B \\
\hline 2 & SGN-U338973 & ribulose bisphosphate carboxylase small chain 3B \\
\hline 3 & SGN-U316742 & Chaperonin 60 beta \\
\hline 3 & SGN-U312543 & Rubisco activase \\
\hline 3 & SGN-U312544 & Rubisco activase \\
\hline 3 & SGN-U312538 & $60 \mathrm{kDa}$ chaperonin alpha subunit \\
\hline 3 & SGN-U312542 & $60 \mathrm{kDa}$ chaperonin alpha subunit \\
\hline \multicolumn{3}{|r|}{ Reduction } \\
\hline 4 & SGN-U313176 & phosphoglycerate kinase \\
\hline 5 & SGN-U312802 & glyceraldehyde-3-phosphate dehydrogenase B subunit \\
\hline 5 & SGN-U312804 & glyceraldehyde-3-phosphate dehydrogenase B subunit \\
\hline 5 & SGN-U312461 & glyceraldehyde-3-phosphate dehydrogenase B subunit \\
\hline \multicolumn{3}{|r|}{ Regeneration } \\
\hline 6 & SGN-U313729 & triose-phosphate isomerase \\
\hline 7 & SGN-U314788 & fructose-bisphosphate aldolase \\
\hline 7 & SGN-U314787 & fructose-bisphosphate aldolase \\
\hline 7 & SGN-U312608 & fructose-bisphosphate aldolase \\
\hline 7 & SGN-U312609 & fructose-bisphosphate aldolase \\
\hline 7 & SGN-U312344 & fructose-bisphosphate aldolase \\
\hline 8 & SGN-U316424 & fructose-1,6-bisphosphatase \\
\hline 9 & SGN-U312320 & Transketolase \\
\hline 9 & SGN-U312319 & Transketolase \\
\hline 9 & SGN-U312322 & Transketolase \\
\hline 9 & SGN-U323721 & Transketolase \\
\hline 10 & SGN-U315559 & sedoheptulose-bisphosphatase \\
\hline 11 & SGN-U312320 & Transketolase \\
\hline 11 & SGN-U312319 & Transketolase \\
\hline 11 & SGN-U312322 & Transketolase \\
\hline 11 & SGN-U323721 & Transketolase \\
\hline 12 & SGN-U313308 & ribulose-phosphate 3-epimerase \\
\hline 13 & SGN-U315528 & ribose 5-phosphate isomerase \\
\hline 14 & SGN-U312791 & phosphoribulokinase \\
\hline
\end{tabular}

(b)

Figure 2: Presence of proteins of the Calvin cycle in the tomato chromoplastic proteome. Proteins are indicated by white squares inside black frames and represented by their generic name and unigene SGN code. Numbers represent the position of the protein in the cycle. Data are derived from [16]. 


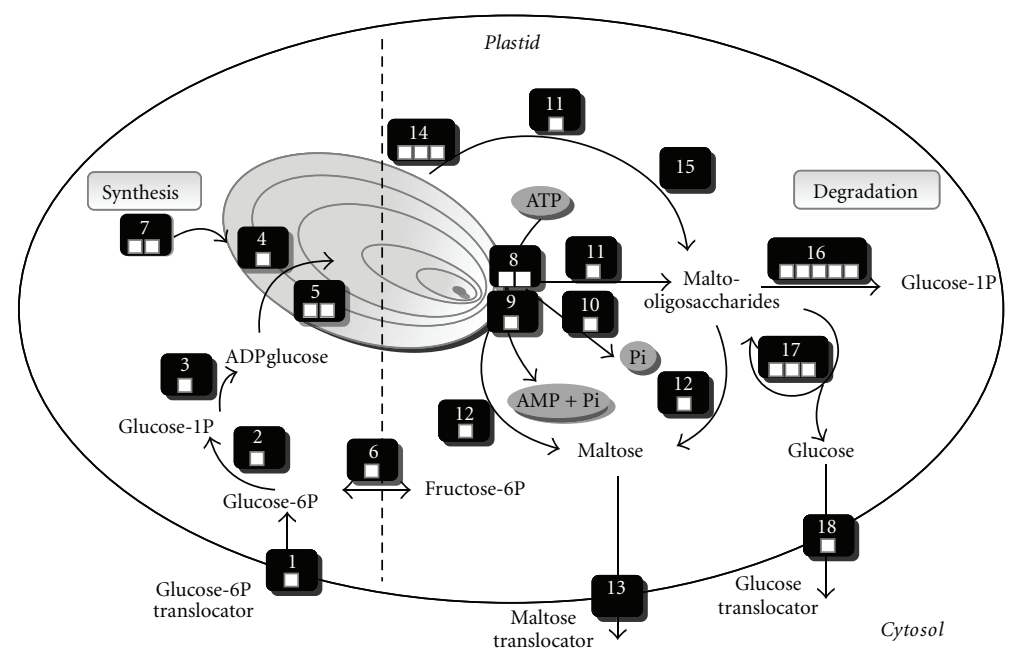

(a)

\begin{tabular}{|r|l|l|}
\hline \multicolumn{3}{|c|}{ Starch synthesis } \\
\hline 1 & SGN-U330538 & Glucose-6-phosphate translocator \\
\hline 2 & SGN-U324006 & Phosphoglucomutase \\
\hline 2 & SGN-U312467 & Phosphoglucomutase \\
\hline 3 & SGN-U317866 & ADP-glucosepyro phosphorylase \\
\hline 4 & SGN-U318293 & Starch synthase I \\
\hline 5 & SGN-U312423 & Starch branching enzyme \\
\hline 5 & SGN-U312427 & Starch branching enzyme \\
\hline 6 & SGN-U317897 & Phosphoglucose isomerase \\
\hline \multicolumn{3}{|c|}{ Post translational regulation of starch synthesis } \\
\hline 7 & SGN-U313499 & $14-3-3-l i k e$ protein GF14 mu \\
\hline 7 & SGN-U316857 & $14-3-3-l i k e$ protein GF14 mu \\
\hline \multicolumn{3}{|c|}{ Starch degradation } \\
\hline 8 & SGN-U328612 & Phosphoglucan-water dikinase \\
\hline 9 & SGN-U315116 & Glucan-water dikinase or SEX1 \\
\hline 10 & SGN-U317732 & Phosphoglucan phosphatase or SEX4 \\
\hline 11 & SGN-U328875 & Isoamylase3 \\
\hline 11 & SGN-U333011 & Isoamylase3 \\
\hline 12 & SGN-U313315 & $\beta$ amylase3 \\
\hline 13 & ABSENT & Maltose translocator or RCP1 \\
\hline 14 & SGN-U317456 & $\alpha$ amylase3 \\
\hline 14 & SGN-U326232 & $\alpha$ amylase3 \\
\hline 14 & SGN-U326817 & $\alpha$ amylase3 \\
\hline 15 & ABSENT & Limit dextrinase \\
\hline 16 & SGN-U316416 & $\alpha$ glucan phosphorylase \\
\hline 16 & SGN-U316417 & $\alpha$ glucan phosphorylase \\
\hline 16 & SGN-U333374 & $\alpha$ glucan phosphorylase \\
\hline 16 & SGN-U325849 & $\alpha$ glucan phosphorylase \\
\hline 16 & SGN-U345057 & $\alpha$ glucan phosphorylase \\
\hline 17 & SGN-U322816 & Disproportionating enzyme 1 \\
\hline 17 & SGN-U333138 & Disproportionating enzyme 1 \\
\hline 17 & SGN-U342143 & Disproportionating enzyme 1 \\
\hline 18 & SGN-U319050 & Glucose translocator \\
\hline
\end{tabular}

(b)

FIgURE 3: Presence of proteins of the starch synthesis and degradation pathways, of posttranslational regulation of starch synthesis, and of sugar translocators in the tomato chromoplastic proteome. Proteins are indicated by white squares inside black frames and represented by their generic name and unigene SGN code. Numbers represent the position of the protein in the cycle. Data are derived from [16]. 
carotenoid storage structures. These newly synthesized membranes are not derived from the thylakoids but rather from vesicles generated from the inner membrane of the plastid [47]. Key proteins for the synthesis of phospholipids, glycolipids, and sterols were identified [16] along with some proteins involved in the lipoxygenase (LOX) pathway. They have been described in the chloroplast, and they lead to the formation oxylipins, which are important compounds for plant defense responses [48]. In the tomato chromoplast, all proteins potentially involved in the LOX pathway leading to the generation of aroma volatiles were found [16].

The shikimate pathway, which is present in microorganisms and plants and never in animals, is a branch point between the metabolism of carbohydrates and aromatic compounds. It leads to the biosynthetic of the aromatic amino acids tyrosine, tryptophan, and phenylalanine [49]. The presence of an active shikimate pathway has been demonstrated in chromoplasts isolated from wild buttercup petals by measuring the activity of the shikimate oxidoreductase [50], and a number of proteins involved in the shikimate pathway have been encountered in the tomato chromoplast proteome [16]. The aromatic amino acids derived from the shikimate pathway are the precursors of a number of important secondary metabolites. Tyrosine is the precursor of tocopherols and tocotrienols. Tryptophane is involved in the synthesis of indole alkaloids which are essential for the generation of some glucosinolates, terpenoids, and tryptamine derivatives [50]. Phenylalanine is the precursor of several classes of flavonoids, including anthocyanins. It is also a precursor for the biosynthesis of volatile compounds which are important for fruit flavor and flower scent, eugenol, 2-phenylacetaldehyde and, 2-phenylethanol [51, 52]. In tomato fruit, for instance, 2-phenylacetaldehyde and 2-phenylethanol are generated from phenylalanine by an aromatic amino acid decarboxylase and a phenylacetaldehyde reductase, respectively $[53,54]$. Nevertheless, there is no indication that the synthesis of the secondary metabolites derived from the shikimate pathway takes place in the chromoplast.

During fruit ripening, an increased synthesis of $\alpha$ tocopherol was observed [55]. The biosynthesis of $\alpha$ tocopherol was localized in the envelope membranes of the Capsicum annum [56], and the almost complete set of proteins of the pathway were present in the tomato chromoplast [16]. The accumulation of $\alpha$-tocopherol, by protecting membrane lipids against oxidation, may contribute to delaying senescence [57].

\section{Plastoglobuli, Plastoglobules, and the Chloroplast-to-Chromoplast Transition}

Plastoglobules are lipoprotein particles present in chloroplasts (Figure 1) and other plastids. They have been recently recognized as participating in some metabolic pathways [58]. For instance, plastoglobules accumulate tocopherols and harbor a tocopherol cyclase, an enzyme catalyzing the conversion of 2,3-dimethyl-5-phytyl-1,4-hydroquinol to $\gamma$ tocopherol [59]. Plastoglobuli also accumulate carotenoids as crystals or as long tubules named fibrils [60, 61]. Part of the enzymes involved in the carotenoid biosynthesis pathway $(\zeta$-carotene desaturase, lycopene $\beta$ cyclase, and two $\beta$ carotene $\beta$ hydroxylases) were found in the plastoglobuli [62].

Plastoglobules arise from a blistering of the stromaside leaflet of the thylakoid membrane [63], and they are physically attached to it [45]. During the chloroplast-tochromoplast transition, a change in the size and number of plastoglobuli was observed (Figure 1). They are larger and more numerous than in the chloroplast [7]. Plastoglobules are the predominant proteins of plastoglobules. Several types of plastoglobules have been described: fibrillin, plastid lipidassociated proteins (PAP) and carotenoid-associated protein (CHRC). All plastoglobules participate in the accumulation of carotenoids in the plastoglobule structure. Carotenoids accumulate as fibrils to form supramolecular lipoprotein structures. A model for fibril assembly has been proposed in which the core is occupied by carotenoids that interact with polar galacto- and phospho-lipids. Fibrillin molecules are located at the periphery in contact with the plastid stroma [64]. In tomato, the overexpression of a pepper fibrillin caused an increase in carotenoid and carotenoid-derived flavour volatiles [47] along with a delayed loss of thylakoids during the chloroplast-to-chromoplast transition. In fibrillin overexpressing tomato, the plastids displayed a typical chromoplastic zone contiguous with a preserved chloroplastic zone. PAP is another major protein of plastoglobules that also participates in the sequestration of carotenoids $[64,65]$. As for CHRC, its downregulation resulted in a $30 \%$ reduction of carotenoids in tomato flowers [66]. Plastoglobuli are, therefore, complex assemblies that play a key role in carotenoid metabolism and greatly influence the evolution of the internal structure of the plastid during the chloroplast to chromoplast transition.

\section{A key Player in Chromoplast Differentiation: The Or Gene}

The Or gene was discovered in cauliflower where the dominant mutation $\mathrm{Or}$ conferred an orange pigmentation with the accumulation of $\beta$-carotene mostly in the inflorescence [67]. The Or gene was isolated by positional cloning [68]. It is localized in the nuclear genome and is highly conserved among divergent plant species [69]. The Or protein corresponds to plastid-targeted a DnaJ-like co-chaperone with a cysteine-rich domain lacking the J-domain [68]. DnaJ proteins are known for interacting with Hsp70 chaperones to perform protein folding, assembly, disassembly, and translocation. The Or mutation is not a loss of function mutation as indicated by the absence of phenotype upon RNAi silencing. It is probably a dominant-negative mutation affecting the interaction with Hsp70 chaperones [70]. The $O R$ mutants displayed an arrest in plastid division so that a limited number of chromoplasts (one or two) were present in the affected cells [71]. Potato tubers over-expressing the Or gene accumulate carotenoids [69]. In the OR mutant, the expression of carotenoid biosynthetic genes was unaffected 
and chromoplasts differentiated normally with membranous inclusions of carotenoids similar to those of carrot roots. It is concluded that the $\mathrm{Or}$ gene is not involved in carotenoid biosynthesis but rather creates a metabolic sink for carotenoid accumulation through inducing the formation of chromoplasts [72].

\section{Transcriptional and Translational Activity in the Plastid Undergo Subtle Changes during Chromoplast Biogenesis}

Most proteins present in the plastid are encoded by nuclear genes. The plastid genome encodes around 84 proteins [60]. Restriction enzyme analysis between chloroplasts of leaves and chromoplasts of tomato fruit indicates the absence of rearrangements, losses, or gains in the chromoplastic DNA [61]. During chromoplast differentiation, the global transcriptional activity is stable, except for a limited number of genes such as $a c c D$, encoding a subunit of the acetyl-CoA carboxylase involved in fatty acid biosynthesis, $\operatorname{trnA}$ (tRNAALA), and rpoC2 (RNA polymerase subunit) [15]. Polysome formation within the plastids declined during ripening suggesting that, while the overall RNA levels remain largely constant, plastid translation is gradually downregulated during chloroplast-to-chromoplast differentiation. This trend was particularly pronounced for the photosynthesis gene group. A single exception was observed; the translation of $a c c D$ stayed high and even increased at the onset of ripening [15].

Specific studies of few plastid-localized genes have been carried out. Genes involved in photosynthesis were, as expected, downregulated during chromoplast formation [25]. However, an upregulation of the large subunit of ribulose1,5-bisphosphate carboxylase/oxygenase and the $32 \mathrm{kD}$ photosystem II quinone binding protein genes has been observed in the chromoplasts of squash fruits (Cucurbitae pepo) [62]. A possible explanation would be that these genes could be regulated independently from the plastid differentiation processes. Genes involved in carotenoid biosynthesis such as the lycopene $\beta$-cyclase (CYCB) were upregulated during chromoplast formation in many plants including the wild species of tomato Solanum habrochaites [63].

\section{Changes in Gene Expression during Chromoplast Differentiation in Ripening Tomato}

The availability of proteomic data of tomato chromoplasts [16] and expression data of a wide range of tomato genes (The Tomato Expression Database: http://ted.bti.cornell.edu) [73] allowed classifying genes encoding chromoplastic proteins according to their expression pattern (Table 1). Among the 87 unigenes whose encoded proteins are located in the chromoplast, the biggest functional class corresponds to genes involved in photosynthesis. Most of them (18 out of 24 ) are either permanently (Table $1(\mathrm{c})$ ) or transiently (Table $1(\mathrm{e})$ ) downregulated at the breaker stage. This is in agreement with the dramatic decrease in the photosynthetic activity of the chromoplast. Three of them show constant expression (Table 1(a): U313693 ATP synthase delta chain; U312985 glycine cleavage system H protein; U312532 oxygen-evolving enhancer protein) and three upregulation (Table 1(b): U312690 plastocyanin; U312593 chlorophyll A-B binding protein 4; U314994 phosphoglycolate phosphatase). In the case of Calvin cycle, 5 out of 12 genes (U312344 fructose-bisphosphate aldolase; U312608 fructose-bisphosphate aldolase; U312609 fructose-bisphosphate aldolase; U314254 ribulose bisphosphate carboxylase small chain 1A; U314701 ribulose bisphosphate carboxylase small chain 3B) had a constant decrease during chromoplast differentiation (Table 1(c)). In tomato fruit, the activity of the ribulose-1,5-bisphosphate carboxylase/oxygenase had a constant decrease during fruit ripening [74], which is in line with the transcriptomic and proteomic data. The genes encoding fructose-bisphosphate aldolase isoforms presented different expression profiles being either up- (U314788) or down- (U312344) regulated during tomato fruit ripening. An increase in overall transcript levels for the fructose-1,6-bisphosphate aldolase has been described during ripening [75]. The importance of transcripts and enzyme activity of the various isoforms are unknown. The remaining genes involved in the Calvin cycle showed either increased (Table 1(b); U312802 glyceraldehyde-3-phosphate dehydrogenase B; U312538 RuBisCO subunit binding-protein) or unchanged expression (Table 1(a); U316424 fructose-1,6-bisphosphatase; U312544 ribulose bisphosphate carboxylase/-oxygenase activase). Three genes coding for the OxPPP were found: two of them exhibited a transient increase in expression at the breaker stage (Table 1(d): U315528 ribose 5-phosphate isomeraserelated; U332994 6-phosphogluconate dehydrogenase family protein) and one a transient decrease (Table $1(\mathrm{e})$ : U315064 transaldolase). The 3 genes involved in tetrapyrrole biosynthesis are not part of the chlorophyll synthesis branch and all of them had an increased expression (Table 1(b): U315993 coproporphyrinogen III oxidase; U315267 uroporphyrinogen decarboxylase; U315567 hydroxymethylbilane synthase), suggesting that the synthesis of tetrapyrroles continues during the transition from chloroplast to chromoplast. As expected, most of the genes (5 out of 6) coding for enzymes involved in carotenoid synthesis showed continuous (Table 1(b): U314429 phytoene synthase; U315069 isopentenyl-diphosphate delta-isomerase II; U316915 geranylgeranyl pyrophosphate synthase; U318137 phytoene dehydrogenase) or transient (Table 1(d): U313450 geranylgeranyl reductase) upregulation. The precursors for carotenoid production are synthesized through the methylerythritol phosphate (MEP) pathway. The gene encoding hydroxymethylbutenyl 4-diphosphate synthase (HDS) (U314139) downstream in the pathway has stable expression (Table 1(a)). This is consistent with previous studies that showed that there were no significant changes in HDS gene expression during tomato fruit ripening [76]. 
TABLE 1: Expression profile analysis of 87 genes whose products are targeted to tomato chromoplasts $\left(^{*}\right)$.

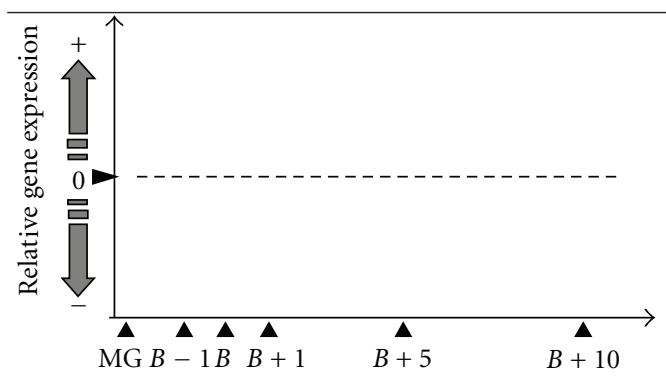

(a)

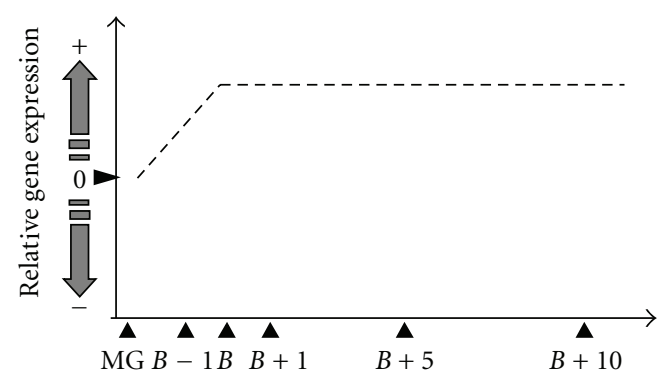

(b)

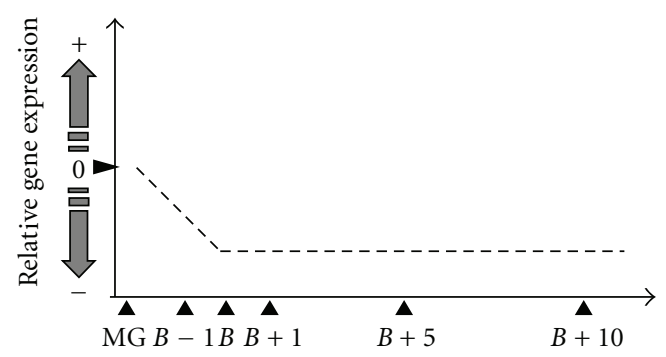

(c)
Photosystem: U313693 ATP synthase delta chain; U312985 glycine cleavage system H protein; U312532 oxygen-evolving enhancer protein. Calvin cycle: U316424 fructose-1, 6-bisphosphatase; U312544 ribulose bisphosphate carboxylase/-oxygenase activase.

Secondary metabolism: U314139 1-hydroxy-2-methyl-2-(E)-butenyl 4-diphosphate synthase.

Photosystem: U312690 plastocyanin; U312593 chlorophyll A-B binding protein 4; U314994 phosphoglycolate phosphatase.

Calvin cycle: U314788 fructose-bisphosphate aldolase; U312802 glyceraldehyde-3-phosphate dehydrogenase B; U312538 RuBisCO subunit binding-protein.

Redox: U314092 L-ascorbate peroxidase; U319145 thioredoxin family protein; U320487 monodehydroascorbate reductase.

Amino acid metabolism: U321505 anthranilate synthase; U317466 3-phosphoshikimate 1-Carboxyvinyltransferase; U317564 tryptophan synthase.

Lipid metabolism: U315474 3-oxoacyl-(acyl-carrier-protein) synthase I; U315475 3-oxoacyl-(acyl-carrier-protein) synthase I; U313753 pyruvate dehydrogenase E1 component. Major CHO metabolism: U315116 starch excess protein (SEX1); U333011 isoamylase, putative; U312423 1, 4-alpha-glucan branching enzyme; U312427 1, 4-alpha-glucan branching enzyme.

Secondary metabolism: U314429 phytoene synthase; U315069

isopentenyl-diphosphate delta-isomerase II; U316915 geranylgeranyl pyrophosphate synthase; U318137 phytoene dehydrogenase.

Tetrapyrrole synthesis: U315993 coproporphyrinogen III oxidase; U315267 uroporphyrinogen decarboxylase; U315567 hydroxymethylbilane synthase. Mitochondrial electron transport: U316255 NADH-ubiquinone oxidoreductase.

Fermentation, ADH: U314358 alcohol dehydrogenase (ADH).

Miscellaneous, cytochrome P450: U313813 NADPH-cytochrome p450 reductase.

S-assimilation. APS: U313496 sulfate adenylyltransferase 1.

Development unspecified: U316277 senescence-associated protein (SEN1). Cell organisation: U313480 plastid lipid-associated protein PAP, putative.

Hormone metabolism: U315633 lipoxygenase.

N-metabolism ammonia metabolism: U323261 glutamate synthase (GLU1). Stress abiotic heat: U315717 HS protein 70.

Not assigned, No ontology: U317890 hydrolase, alpha/beta fold family protein.

Photosystem: U312531 oxygen-evolving enhancer protein; U313447

photosystem I reaction center subunit IV; U313204 chlorophyll A-B binding protein 2; U313245 ATP synthase gamma chain 1; U312436 chlorophyll A-B binding protein; U313211 chlorophyll A-B binding protein 2; U313212 chlorophyll A-B binding protein 2; U313213 chlorophyll A-B binding protein 2; U312572 photosystem II oxygen-evolving complex 23 (OEC23); U314260 photosystem I reaction center subunit III family protein.

Calvin cycle: U312344 fructose-bisphosphate aldolase; U312608

fructose-bisphosphate aldolase; U312609 fructose-bisphosphate aldolase; U314254 ribulose bisphosphate carboxylase small chain 1A; U314701 ribulose bisphosphate carboxylase small chain 3B.

Lipid metabolism: U319207 phosphatidylglycerol phosphate synthase (PGS1). Redox: U313537 dehydroascorbate reductase.

Major CHO metabolism: U316416 glucan phosphorylase, putative.

N-metabolism: U314517 glutamine synthetase (GS2).

Amino acid metabolism: U317344 bifunctional aspartate kinase/homoserine dehydrogenase; U320667 cystathionine beta-lyase. 
TABLE 1: Continued.

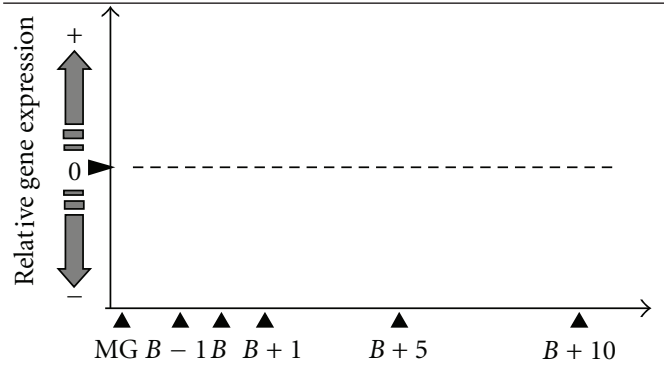

(a)

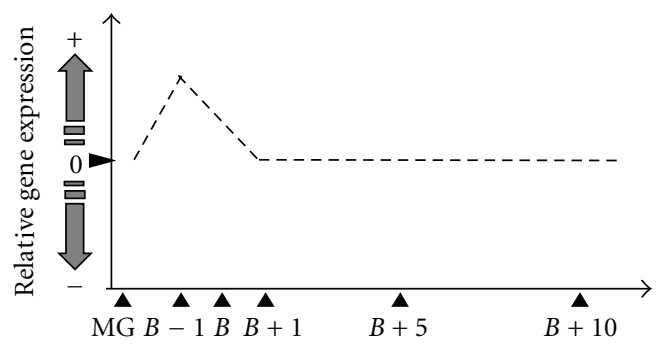

(d)

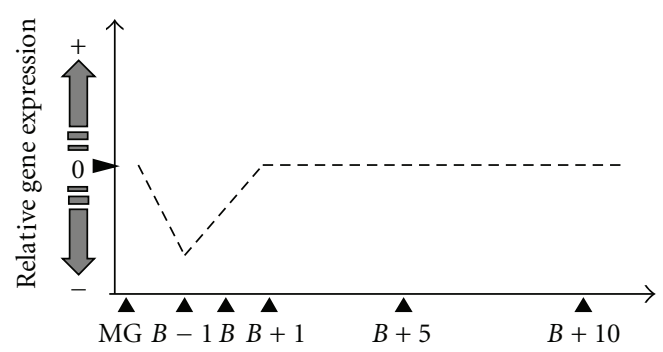

(e)
Photosystem: U313693 ATP synthase delta chain; U312985 glycine cleavage system H protein; U312532 oxygen-evolving enhancer protein. Calvin cycle: U316424 fructose-1, 6-bisphosphatase; U312544 ribulose bisphosphate carboxylase/-oxygenase activase. Secondary metabolism: U314139 1-hydroxy-2-methyl-2-(E)-butenyl 4-diphosphate synthase.

Redox: U314061 peroxiredoxin Q; U314093 L-ascorbate peroxidase, thylakoid-bound (tAPX); U314923 2-cys peroxiredoxin. OPP, Nonreductive PP: U315528 ribose 5-phosphate isomerase related; U332994 6-phosphogluconate dehydrogenase family protein; U316131 6-phosphogluconate dehydrogenase NAD-binding domain-containing protein.

Secondary metabolism: U317741 acetyl coenzyme A carboxylase carboxyl transferase alpha subunit family; U313450 geranylgeranyl reductase.

Amino acid metabolism: U317245 tryptophan synthase related.

$\mathrm{N}$-metabolism ammonia metabolism: U317524 ferredoxin-nitrite reductase. Lipid metabolism: U315697 enoyl-(acyl-carrier protein) reductase (NADH) U321151 lipoxygenase.

Transport metabolite: U312460 triose phosphate/phosphate translocator, putative.

Signalling calcium: U315961 calnexin 1 (CNX1).

Photosystem: U312843 chlorophyll A-B binding protein; U312858 cytochrome B6-F complex iron-sulfur subunit; U313214 chlorophyll A-B binding protein 2; U312791 phosphoribulokinase (PRK); U317040 photosystem II reaction center PsbP family protein; U312449 chlorophyll A-B binding protein CP26; U312661 chlorophyll A-B binding protein CP29 (LHCB4); U313789 ATP synthase family.

Calvin cycle: U312461 glyceraldehyde 3-phosphate dehydrogenase A; U312871 oxygen-evolving enhancer protein 3.

Redox: U315728 glutathione peroxidase.

OPP nonreductive PP transaldolase: U315064 transaldolase.

Signaling calcium: U318939 calcium-binding EF hand family protein. Major CHO metabolism: U313315 beta amylase.

(*) Genes represented in this table are filtered from TED database [64] crossing with the proteins described by Barsan et al. [16]. The expression profiles were clustered with the Bioinformatics tools of the Matlab (MathWorks) software package and further reduced to five representative expression profiles according to their general tendencies represented in the first column. The expression values used in this analysis were taken from experiment E011 from TED database. Relative expression refers to the ratio between the expression values of each ripening point and MG. All data were normalized by the mean and log2 transformed. (a) Genes that remain stable during the ripening, (b) genes that have an increase or (c) a decrease until breaker stage and then reaches a plateau, (d) genes that have a positive or (e) negative transient expression around the breaker stage. (MG, mature green; $B-1,1 \mathrm{~d}$ before breaker; $B$, breaker stage; $B+$ $1,1 \mathrm{~d}$ after breaker; $B+5,5 \mathrm{~d}$ after breaker; $B+10,10 \mathrm{~d}$ after breaker.)

In the case of lipid metabolism, three genes showed increased expression (Table 1(b): U315474 3-oxoacyl-(acylcarrier-protein) synthase I; U315475 3-oxoacyl-(acyl-carrierprotein) synthase I; U313753 pyruvate dehydrogenase E1 component), and two genes had transient increase (Table 1(d): U315697 enoyl-(acyl-carrier protein) reductase (NADH); U321151 lipoxygenase). Phosphatidylglycerol phosphate synthase showed decreased expression (Table 1(c)). This enzyme is involved in the biosynthesis of phosphatidylglycerol and is considered as playing an important role in the ordered assembly and structural maintenance of the photosynthetic apparatus in thylakoid membranes and in the functioning of the photosystem II [77]. The downregulation of this gene during chromoplast differentiation is consistent with thylakoid disintegration and photosynthesis disappearance.

Four genes of the starch metabolism present upregulation (Table 1(b)). Two of them are part of the starch biosynthesis (U312423 1,4-alpha-glucan branching enzyme; U312427 1, 4-alpha-glucan branching enzyme), and one of them is involved starch degradation U315116 starch excess protein (SEX1). The fourth one, an isoamylase (U333011) can participate either in starch degradation or in starch synthesis, depending on the isoform [78]. The expression of the gene that codes a starch degrading glucan phosphorylase (U316416) decreases, and the expression of another starch degrading gene, beta-amylase (U313315), has a negative transient expression (Table 1(b)). In addition, proteomic 
studies have shown the presence of two starch excess proteins (SEX1 and 4) that probably contribute to the absence of starch accumulation [16]. Starch is degraded during the chloroplast to chromoplast transition to provide carbon and energy necessary to sustain the metabolic activity during fruit ripening. Several enzymes are responsible for the processes, each one possessing several isoforms with different regulatory mechanisms [78].

Interestingly genes involved in aroma production such as $A D H$ (U314358) or LOXC (U315633) had a constant increase in gene expression (Table $1(\mathrm{~b})$ ). This could be related to the increase in aroma production via the LOX pathway.

The microarray data discussed in this section cover a wide range of the tomato transcriptome. However, several isoforms of several genes are not represented in the database, which could explain some contradictory patterns of expression encountered in our analysis. Nevertheless, although not providing a full picture of the molecular events occuring during the chloroplast to chromoplast transition, these data confirm the regulation at the transcriptional level of the most salient events.

\section{Conclusions and Perspectives}

With the advent of high throughput technologies, great progress has been made in the recent years in the elucidation of the structure and function of plastids. The most important data obtained in the area have been generated for the chloroplast of Arabidopsis. Much less information is available for the chromoplast. However, recent studies with bell pepper [14] and tomato fruit [16] have allowed assigning to chromoplasts a number of proteins around 1000, which is in the same order of magnitude as Arabidopsis chloroplasts [33]. This number is, however, much lower than the number of proteins predicted to be located in the plastid which has been estimated at up to 2700 [79] or even 3800 [80]. The increased sensitivity of the mass spectrometry technologies associated with efficient methods of purification of plastids, particularly chromoplasts, will allow in the future identifying more proteins. So far, changes in the proteome have not been described during the differentiation of chromoplast. Such studies imply the development of efficient protocols for isolating plastids at different stages of differentiation during chromoplastogenesis. The combination of proteomics and transcriptomics may also give novel information on the process in a near future. The discovery of the $\mathrm{Or}$ gene has been a great step forward to the understanding of the molecular determinism of chromoplast differentiation. There is a need to better understand the regulatory mechanism controlling the expression of the Or gene. Many genes encoding for plastidial proteins are regulated by the plant hormone ethylene and, therefore, participate in the transcriptional regulation of the fruit ripening process in general $[81,82]$. Other hormones such as ABA and auxin may also be involved. Interactions between hormones and other signals (light, for instance) during chromoplast differentiation represent another field of investigation to be explored. Because most of the proteins present in the chromoplast are encoded by nuclear genes, it will be important in future to better understand the changes occurring in the processes of transport of proteins to the chromoplast. It is suspected that vesicular transport is gaining importance, but more experimental evidence is required. Finally the dialog between the nucleus and the chromoplast and the signals involved needs to be explored. So far most of the studies in this area have been carried out with chloroplasts [83].

In conclusion, important steps forward have been made into a better understanding of chromoplast differentiation. Metabolic reorientations and specific biochemical and molecular events have been clearly identified. It is predictable that more information will arise from the indepth description of the molecular events occurring during the chloroplast to chromoplast transition using genomic tools.

\section{Acknowledgments}

Wanping Bian has received a bursary from the University of Chongqing (China) for a Ph. D. and Cristina Barsan from the French Embassy in Bucharest (Romania) for a joint "co-supervision" Ph. D. The "Fundación Séneca" (Murcia, Spain)" provided a postdoctoral fellowship to Isabel Egea and the government of Brazil (CNPq) a sabbatical fellowship to Eduardo Purgatto. The authors acknowledge the MidiPyrénées Regional Council for financial support. W. Bian and C. Barsan are participated equally to the work.

\section{References}

[1] B. Bathgate, M. E. Purton, D. Grierson, and P. W. Goodenough, "Plastid changes during the conversion of chloroplasts to chromoplasts in ripening tomatoes," Planta, vol. 165, no. 2 , pp. 197-204, 1985.

[2] Y. Ben-Shaul, T. Treffry, and S. Klein, "Fine structure studies of carotene body development," Journal de Microscopie (Paris), vol. 7, pp. 265-274, 1968.

[3] M. G. Grilli Caiola and A. Canini, "Ultrastructure of chromoplasts and other plastids in Crocus sativus L. (Iridaceae)," Plant Biosystems, vol. 138, no. 1, pp. 43-52, 2004.

[4] H. T. Horner, R. A. Healy, G. Ren et al., "Amyloplast to chromoplast conversion in developing ornamental tobacco floral nectaries provides sugar for nectar and antioxidants for protection," American Journal of Botany, vol. 94, no. 1, pp. 1224, 2007.

[5] W. W. Thomson and J. M. Whatley, "Development of nongreen plastids," Annual Review of Plant Physiology, vol. 31, pp. 375-394, 1980.

[6] B. Camara, P. Hugueney, F. Bouvier, M. Kuntz, and R. Monegér, "Biochemistry and molecular biology of chromoplast development," International Review of Cytology, vol. 163, pp. 175-247, 1995.

[7] W. M. Harris and A. R. Spurr, "Chromoplasts of tomato fruit. II. The red tomato," American Journal of Botany, vol. 56, pp. 380-389, 1969.

[8] J. A. Laborde and A. R. Spurr, "Chromoplast ultrastructure as affected by genes controlling grana retention and carotenoids in fruits of Capsicum annuum," American Journal of Botany, vol. 60, pp. 736-744, 1973. 
[9] N. Ljubesic, M. Wrischer, and Z. Devide, "Chromoplasts-the last stages in plastid development," International Journal of Developmental Biology, vol. 35, no. 3, pp. 251-258, 1991.

[10] M. R. Marano, E. C. Serra, G. Orellano, and N. Carrillo, "The path of chromoplast development in fruits and flowers," Plant Science, vol. 94, no. 1-2, pp. 1-17, 1993.

[11] F. Bouvier and B. Camara, "The role of plastids in ripening fruits," in The Structure and Functions of Plastids, R. R. Wise and J. K. Hoober, Eds., pp. 419-432, Springer, Dordrecht, The Netherlands, 2007.

[12] K. Pyke, "Plastid biogenesis and differentiation," in Cell and Molecular Biology of Plastids, R. Bock, Ed., vol. 19 of Topics in Current Genetic, pp. 1-28, Springer, Berlin, Germany, 2007.

[13] E. Lopez-Juez, "Plastid biogenesis, between shadow and light," Journal of Experimental Botany, vol. 58, no. 1, pp. 11-26, 2007.

[14] M. A. Siddique, J. Grossmann, W. Gruissem, and S. Baginsky, "Proteome analysis of bell pepper (Capsicum annuum L.) chromoplasts," Plant and Cell Physiology, vol. 47, no. 12, pp. 1663-1673, 2006.

[15] S. Kahlau and R. Bock, "Plastid transcriptomics and translatomics of tomato fruit development and chloroplast-tochromoplast differentiation: chromoplast gene expression largely serves the production of a single protein," The Plant Cell, vol. 20, no. 4, pp. 856-874, 2008.

[16] C. Barsan, P. Sanchez-Bel, C. Rombaldi et al., "Characteristics of the tomato chromoplast proteome revealed by proteomic analysis," Journal of Experimental Botany, vol. 61, no. 9, pp. 2413-2431, 2010.

[17] A. R. Spurr and W. M. Harris, "Ultrastructure of chloroplasts and chromoplasts in Capsicum annuum. I. Thylakoid membrane changes during fruit ripening," American Journal of Botany, vol. 55, pp. 1210-1224, 1968.

[18] R. H. Köhler and M. R. Hanson, "Plastid tubules of higher plants are tissue-specific and developmentally regulated," Journal of Cell Science, vol. 113, no. 1, pp. 81-89, 2000.

[19] M. T. Waters, R. G. Fray, and K. A. Pyke, "Stromule formation is dependent upon plastid size, plastid differentiation status and the density of plastids within the cell," The Plant Journal, vol. 39, no. 4, pp. 655-667, 2004.

[20] P. Jarvis, "Targeting of nucleus-encoded proteins to chloroplasts in plants," New Phytologist, vol. 179, no. 2, pp. 257-285, 2008.

[21] S. Miras, D. Salvi, M. Ferro et al., "Non-canonical transit peptide for import into the choloroplast," Journal of Biological Chemistry, vol. 227, pp. 4770-4778, 2002.

[22] S. Westphal, J. Soll, and U. C. Vothknecht, "A vesicle transport system inside chloroplasts," FEBS Letters, vol. 506, no. 3, pp. 257-261, 2001.

[23] M. X. Andersson and A. S. Sandelius, "A chloroplast-localized vesicular transport system: a bio-informatics approach," BMC Genomics, vol. 5, article 40, 2004.

[24] P. D. Fraser, M. R. Truesdale, C. R. Bird, W. Schuch, and P. M. Bramley, "Carotenoid biosynthesis during tomato fruit development," Plant Physiology, vol. 105, no. 1, pp. 405-413, 1994.

[25] I. Egea, W. Bian, C. Barsan et al., "Chloroplast-to-chromoplast transition in tomato fruit: spectral confocal microscopy analyses of carotenoids and chlorophylls in isolated plastids and time-lapse recording on intact live tissue," Annals of Botany. In press.

[26] A. Y. Cheung, T. McNellis, and B. Piekos, "Maintenance of chloroplast components during chromoplast differentiation in the tomato mutant green flesh," Plant Physiology, vol. 101, no. 4, pp. 1223-1229, 1993.

[27] R. Alba, Z. Fei, P. Payton et al., "ESTs, cDNA microarrays, and gene expression profiling: tools for dissecting plant physiology and development," The Plant Journal, vol. 39, no. 5, pp. 697714, 2004.

[28] S. Carrara, A. Pardossi, G. F. Soldatini, F. Tognoni, and L. Guidi, "Photosynthetic activity of ripening tomato fruit," Photosynthetica, vol. 39, no. 1, pp. 75-78, 2001.

[29] G. Ronen, M. Cohen, D. Zamir, and J. Hirschberg, "Regulation of carotenoid biosynthesis during tomato fruit development: expression of the gene for lycopene epsilon-cyclase is downregulated during ripening and is elevated in the mutant delta," The Plant Journal, vol. 17, no. 4, pp. 341-351, 1999.

[30] Y. Libal-Weksler, M. Vishnevetsky, M. Ovadis, H. Itzhaki, and A. Vainstein, "Flower-specific carotenoid accumulation in chromoplasts: molecular control of carotenoid-associated proteins," Acta Horticulturae, vol. 420, pp. 32-34, 1995.

[31] M. C. Marti, D. Camejo, E. Olmos et al., "Characterisation and changes in the antioxidant system of chloroplasts and chromoplasts isolated from green and mature pepper fruits," Plant Biology, vol. 11, no. 4, pp. 613-624, 2009.

[32] A. Strand, T. Asami, J. Alonso, J. R. Ecker, and J. Chory, "Chloroplast to nucleus communication triggered by accumulation of Mg-protoporphyrinIX," Nature, vol. 421, no. 6918, pp. 79-83, 2003.

[33] M. Ferro, S. Brugière, D. Salvi et al., "AT-CHLORO, a comprehensive chloroplast proteome database with subplastidial localization and curated information on envelope proteins," Molecular and Cellular Proteomics, vol. 9, no. 6, pp. 1063-1084, 2010.

[34] E. Thom, T. Mohlmann, P. W. Quick, B. Camara, and H. E. Neuhaus, "Sweet pepper plastids: enzymic equipment, characterisation of the plastidic pentose-phosphate pathway, and transport of phosphorylated intermediates across the envelope membrane," Planta, vol. 204, no. 2, pp. 226-233, 1998.

[35] H. Obiadalla-Ali, A. R. Fernie, J. Kossmann, and J. R. Lloyd, "Developmental analysis of carbohydrate metabolism in tomato (Lycopersicon esculentum cv. Micro-Tom) fruits," Physiologia Plantarum, vol. 120, no. 2, pp. 196-204, 2004.

[36] K. Aoki, M. Yamamoto, and K. Wada, "Photosynthetic and heterotrophic ferredoxin isoproteins are colocalized in fruit plastids of tomato," Plant Physiology, vol. 118, no. 2, pp. 439$449,1998$.

[37] I. J. Tetlow, C. G. Bowsher, and M. J. Emes, "Biochemical properties and enzymic capacities of chromoplasts isolated from wild buttercup (Ranunculus acris L.)," Plant Science, vol. 165, no. 2, pp. 383-394, 2003.

[38] K. Luengwilai and D. M. Beckles, "Starch granules in tomato fruit show a complex pattern of degradation," Journal of $\mathrm{Ag}$ ricultural and Food Chemistry, vol. 57, no. 18, pp. 8480-8487, 2009.

[39] K. Luengwilai and D. M. Beckles, "Structural investigations and morphology of tomato fruit starch," Journal of Agricultural and Food Chemistry, vol. 57, no. 1, pp. 282-291, 2009.

[40] S. C. Zeeman, J. Kossmann, and A. M. Smith, "Starch: its metabolism, evolution, and biotechnological modification in plants," Annual Review of Plant Biology, vol. 61, pp. 209-234, 2010.

[41] A. Latché, J. C. Pech, and J. Fallot, "Starch breakdown and ripening of apple and pear fruits," Physiologie Végétale, vol. 13, pp. 637-649, 1975.

[42] R. Butowt, D. Granot, and M. I. Rodriguez-Garcia, "A putative plastidic glucose translocator is expressed in heterotrophic 
tissues that do not contain starch, during olive (Olea europea L.) Fruit Ripening," Plant and Cell Physiology, vol. 44, no. 11, pp. 1152-1161, 2003.

[43] I. J. Tetlow, M. K. Morell, and M. J. Emes, "Recent developments in understanding the regulation of starch metabolism in higher plants," Journal of Experimental Botany, vol. 55, no. 406, pp. 2131-2145, 2004.

[44] I. J. Tetlow, R. Wait, Z. Lu et al., "Protein phosphorylation in amyloplasts regulates starch branching enzyme activity and protein-protein interactions," The Plant Cell, vol. 16, no. 3, pp. 694-708, 2004.

[45] P. C. Sehnke, H. J. Chung, K. Wu, and R. J. Ferl, "Regulation of starch accumulation by granule-associated plant 15-3-3 proteins," Proceedings of the National Academy of Sciences of the United States of America, vol. 98, no. 2, pp. 765-770, 2001.

[46] J. Joyard, M. Ferro, C. Masselon et al., "Chloroplast proteomics highlights the subcellular compartmentation of lipid metabolism," Progress in Lipid Research, vol. 49, no. 2, pp. 128 $158,2010$.

[47] A. J. Simkin, J. Gaffé, J. P. Alcaraz et al., "Fibrillin influence on plastid ultrastructure and pigment content in tomato fruit," Phytochemistry, vol. 68, no. 11, pp. 1545-1556, 2007.

[48] T. Farmaki, M. Sanmartin, P. Jimenez et al., "Differential distribution of the lipoxygenase pathway enzymes within potato chloroplasts," Journal of Experimental Botany, vol. 58, no. 3, pp. 555-568, 2007.

[49] K. M. Herrmann, "The shikimate pathway: early steps in the biosynthesis of aromatic compounds," The Plant Cell, vol. 7, no. 7, pp. 907-919, 1995.

[50] V. Tzin and G. Galili, "New Insights into the shikimate and aromatic amino acids biosynthesis pathways in plants," Molecular Plant, vol. 3, no. 6, pp. 956-972, 2010.

[51] E. A. Baldwin, J. W. Scott, C. K. Shewmaker, and W. Schuch, "Flavor trivia and tomato aroma: biochemistry and possible mechanisms for control of important aroma components," HortScience, vol. 35, no. 6, pp. 1013-1022, 2000.

[52] S. Baldermann, Z. Yang, M. Sakai, P. Fleischmann, and N. Watanabe, "Volatile constituents in the scent of roses," Floriculture and Ornamental Biotechnology, vol. 3, pp. 89-97, 2009.

[53] D. Tieman, M. Taylor, N. Schauer, A. R. Fernie, A. D. Hanson, and H. J. Klee, "Tomato aromatic amino acid decarboxylases participate in synthesis of the flavor volatiles 2-phenylethanol and 2-phenylacetaldehyde," Proceedings of the National Academy of Sciences of the United States of America, vol. 103, no. 21, pp. 8287-8292, 2006.

[54] D. Tieman, H. M. Loucas, J. Y. Kim, D. G. Clark, and H. J. Klee, "Tomato phenylacetaldehyde reductases catalyze the last step in the synthesis of the aroma volatile 2-phenylethanol," Phytochemistry, vol. 68, no. 21, pp. 2660-2669, 2007.

[55] H. K. Lichtenthaler, "Zur synthese der lipophilen plastidenchinone und sekundarcarotinoide wahrend der chromoplastenentwicklung," Berichte der Deutschen Botanischen Gesellschaft, vol. 82, pp. 483-497, 1969.

[56] Y. Arango and K. P. Heise, "Localization of a-tocopherol synthesis in chromoplast envelope membranes of Capsicum annuum L. fruits," Journal of Experimental Botany, vol. 49, no. 324, pp. 1259-1262, 1998.

[57] B. Camara, F. Bardat, O. Dogbo, J. Brangeon, and R. Moneger, "Terpenoid metabolism in plastids. Isolation and biochemical characteristics of Capsicum annuum chromoplasts," Plant Physiology, vol. 73, pp. 94-99, 1983.

[58] C. Bréhélin and F. Kessler, "The plastoglobule: a bag full of lipid biochemistry tricks," Photochemistry and Photobiology, vol. 84, no. 6, pp. 1388-1394, 2008.
[59] F. Kessler and P. A. Vidi, "Plastoglobule lipid bodies: their functions in chloroplasts and their potential for applications," Advances in Biochemical Engineering/Biotechnology, vol. 107, pp. 153-172, 2007.

[60] Z. Devide, "Ultrastructural changes of plastids in ripe fruits of Cucurbita pepo cv. Olifera," Acta Botanica Croatica, vol. 29, pp. 57-60, 1970.

[61] N. Ljubesic, "The formation of chromoplasts in fruits of Cucurbita maxima Duch," Turbaniformis, Botanical Gazette, vol. 13, pp. 286-290, 1977.

[62] A. J. Ytterberg, J. B. Peltier, and K. J. van Wijk, "Protein profiling of plastoglobules in chloroplasts and chromoplasts. A surprising site for differential accumulation of metabolic enzymes," Plant Physiology, vol. 140, no. 3, pp. 984-997, 2006.

[63] J. R. Austin, E. Frost, P. Vidi, F. Kessler, and L. A. Staehelin, "Plastoglobules are lipoprotein subcompartments of the chloroplast that are permanently coupled to thylakoid membranes and contain biosynthetic enzymes," The Plant Cell, vol. 18, no. 7, pp. 1693-1703, 2006.

[64] J. Deruere, S. Romer, A. d'Harlingue, R. A. Backhaus, M. Kuntz, and B. Camara, "Fibril assembly and carotenoid overaccumulation in chromoplasts: a model for supramolecular lipoprotein structures," The Plant Cell, vol. 6, no. 1, pp. 119133, 1994.

[65] J. Pozueta-Romero, F. Rafia, G. Houlne et al., "A ubiquitous plant housekeeping gene, PAP, encodes a major protein component of bell pepper chromoplasts," Plant Physiology, vol. 115, no. 3, pp. 1185-1194, 1997.

[66] Y. Leitner-Dagan, M. Ovadis, E. Shklarman, Y. Elad, D. R. David, and A. Vainstein, "Expression and functional analysis of the plastid lipid-associated protein CHRC suggest its role in chromoplastogenesis and stress," Plant Physiology, vol. 142, no. 1, pp. 233-244, 2006.

[67] L. Li, D. J. Paolillo, M. V. Parthasarathy, E. M. DiMuzio, and D. F. Garvin, "A novel gene mutation that confers abnormal patterns of $\beta$-carotene accumulation in cauliflower (Brassica oleracea var. botrytis)," The Plant Journal, vol. 26, no. 1, pp. 59-67, 2001.

[68] S. Lu, J. Van Eck, X. Zhou et al., "The cauliflower Or gene encodes a DnaJ cysteine-rich domain-containing protein that mediates high levels of $\beta$-carotene accumulation," The Plant Cell, vol. 18, no. 12, pp. 3594-3605, 2006.

[69] X. Zhou, J. Van Eck, and L. Li, "Use of the cauliflower Or gene for improving crop nutritional quality," Biotechnology Annual Review, vol. 14, pp. 171-190, 2008.

[70] G. Giuliano and G. Diretto, "Of chromoplasts and chaperones," Trends in Plant Science, vol. 12, no. 12, pp. 529-531, 2007.

[71] D. J. Paolillo, D. F. Garvin, and M. V. Parthasarathy, "The chromoplasts of Or mutants of cauliflower (Brassica oleracea L. var. botrytis)," Protoplasma, vol. 224, no. 3-4, pp. 245-253, 2004.

[72] L. Li and J. van Eck, "Metabolic engineering of carotenoid accumulation by creating a metabolic sink," Transgenic Research, vol. 16, no. 5, pp. 581-585, 2007.

[73] Z. Fei, X. Tang, R. Alba, and J. J. Giovannoni, “Tomato Expression Database (TED): a suite of data presentation and analysis tools," Nucleic Acids Research, vol. 34, pp. 766-770, 2006.

[74] B. A. Martin, J. A. Gauger, and N. E. Tolbert, "Changes in activity of ribulose-1,5 bisphosphate carboxylase/oxygenase and three peroxisomal enzymes during tomato fruit development and ripening," Plant Physiology, vol. 63, pp. 486-489, 1979. 
[75] B. Piechulla, "Differential expression of nuclear- and organelle-encoded genes during tomato fruit development," Planta, vol. 174, no. 4, pp. 505-512, 1988.

[76] M. Rodriguez-Concepcion, J. Querol, L. M. Lois, S. Imperial, and A. Boronat, "Bioinformatic and molecular analysis of hydroxymethylbutenyl diphosphate synthase (GCPE) gene expression during carotenoid accumulation in ripening tomato fruit," Planta, vol. 217, no. 3, pp. 476-482, 2003.

[77] M. Hagio, Z. Gombos, Z. Várkonyi et al., "Direct evidence for requirement of phosphatidylglycerol in photosystem II of photosynthesis," Plant Physiology, vol. 124, no. 2, pp. 795-804, 2000.

[78] A. M. Smith, S. C. Zeeman, and S. M. Smith, "Starch degradation," Annual Review of Plant Biology, vol. 56, pp. 73-96, 2005.

[79] A. H. Millar, J. Whelan, and I. Small, "Recent surprises in protein targeting to mitochondria and plastids," Current Opinion in Plant Biology, vol. 9, no. 6, pp. 610-615, 2006.

[80] T. Kleffmann, D. Russenberger, A. von Zychlinski et al., "The Arabidopsis thaliana chloroplast proteome reveals pathway abundance and novel protein functions," Current Biology, vol. 14, no. 5, pp. 354-362, 2004.

[81] J. Giovannoni, "Molecular regulation of fruit ripening," Annual Review of Plant Physiology and Plant Molecular Biology, vol. 52, pp. 725-749, 2001.

[82] J. Pirrello, F. Regad, A. Latché, J. C. Pech, and M. Bouzayen, "Regulation of tomato fruit ripening," CAB Reviews, vol. 4, no. 9, pp. 1-14, 2009.

[83] H. S. Jung and J. Chory, "Signaling between chloroplasts and the nucleus: can a systems biology approach bring clarity to a complex and highly regulated pathway?" Plant Physiology, vol. 152, no. 2, pp. 453-459, 2010. 

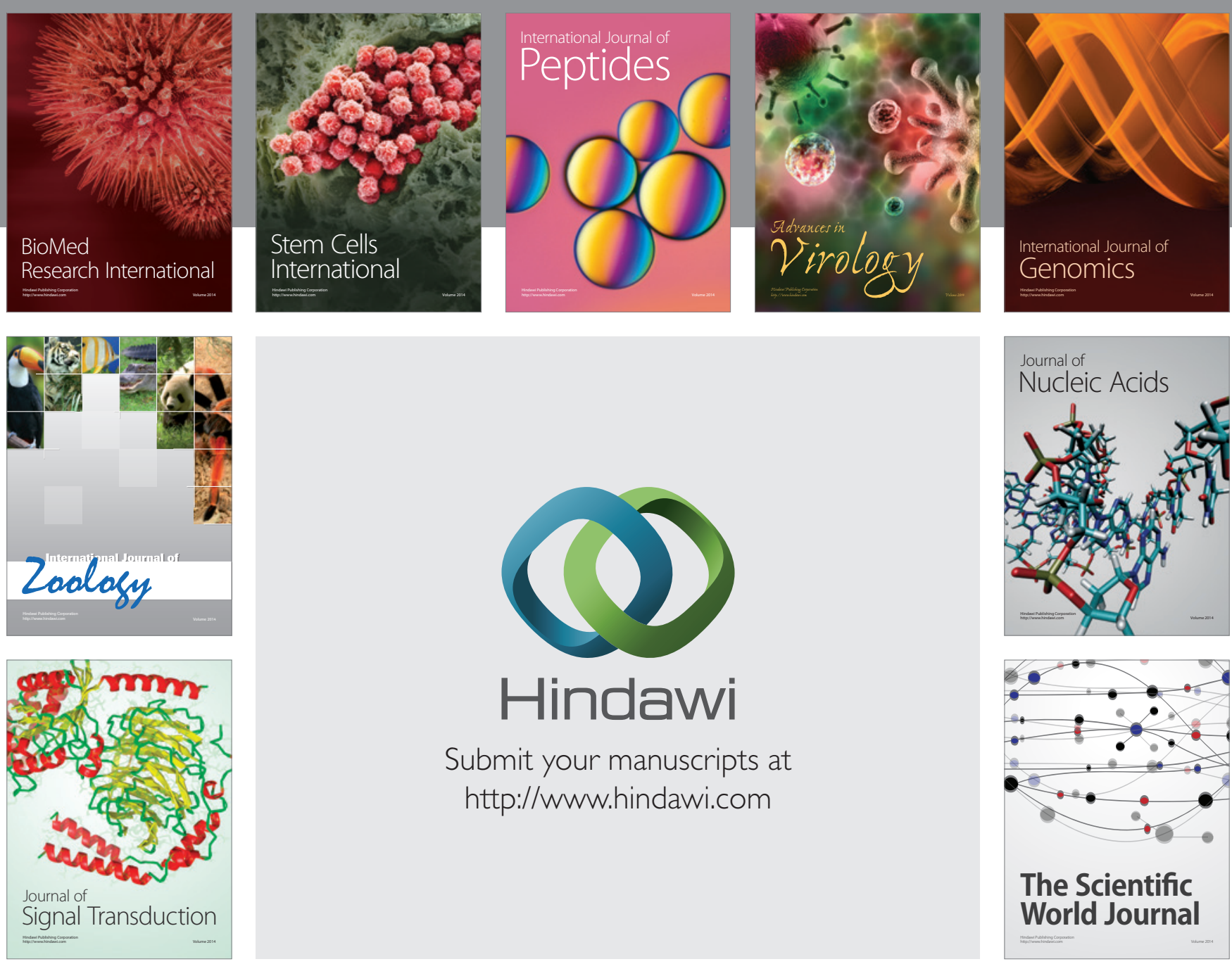

Submit your manuscripts at

http://www.hindawi.com
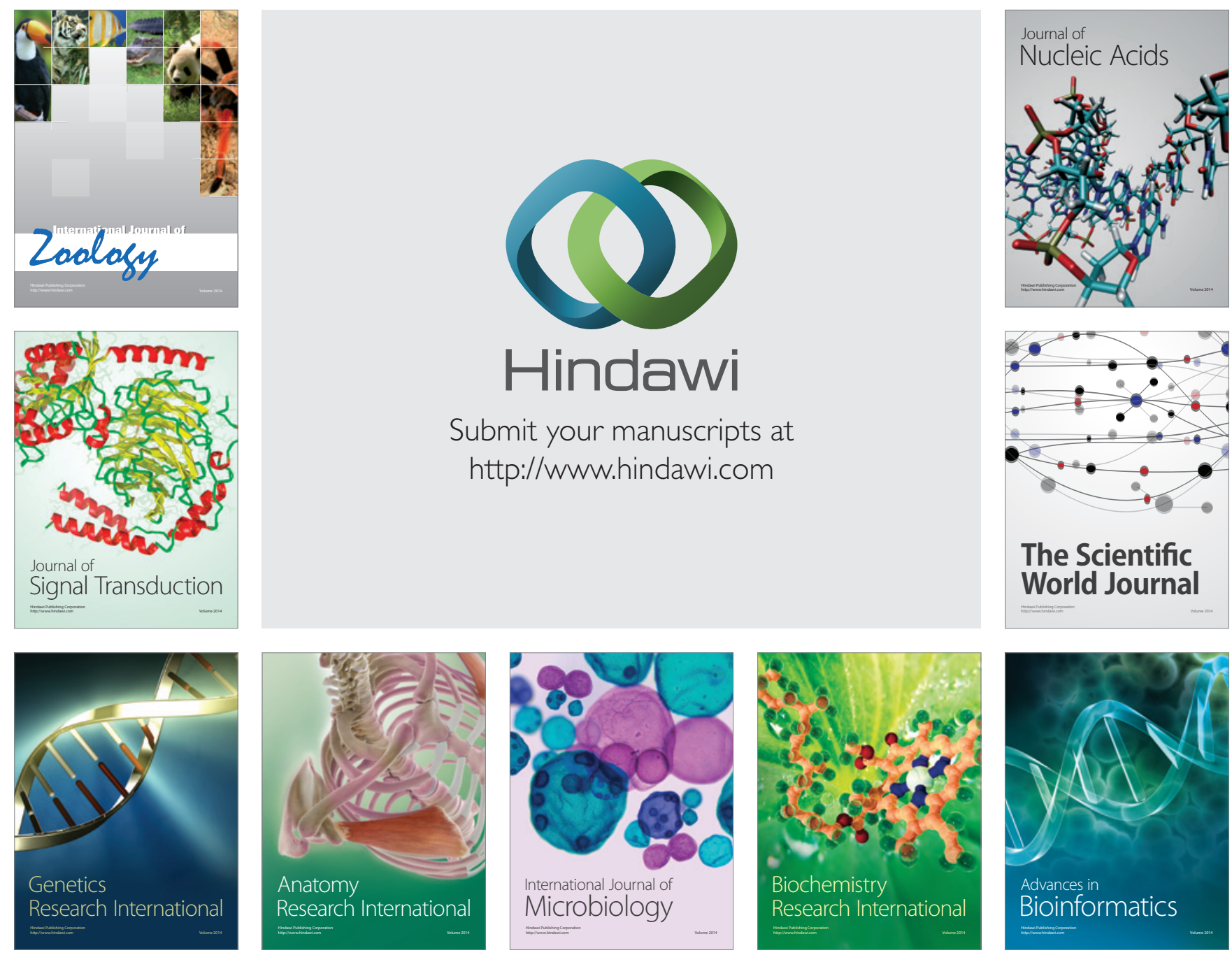

The Scientific World Journal
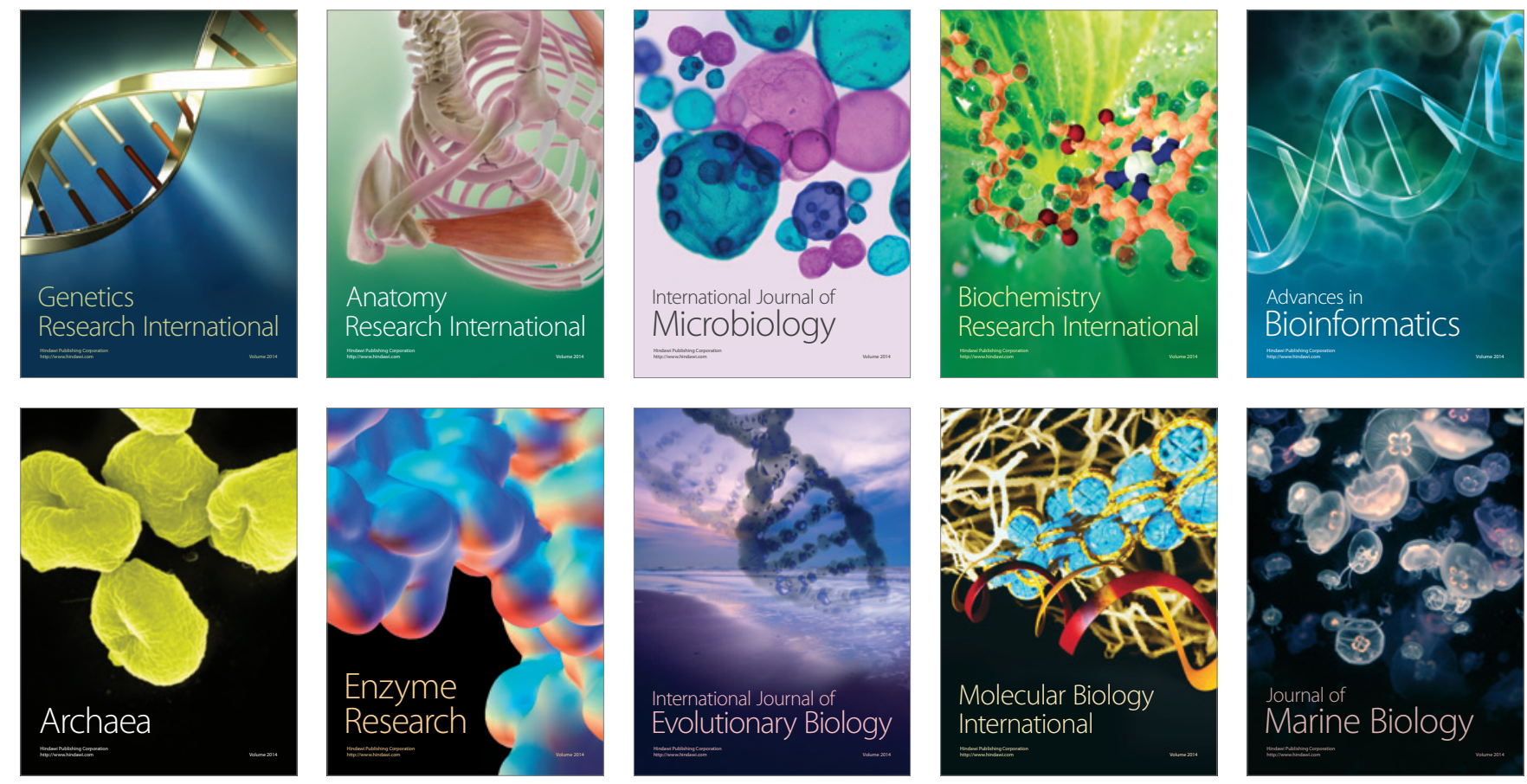